Structural Eng. / Earthquake Eng. Vol.6. No.2, 387s-394s. October 1989

Japan Society of Civil Engineers (Proc. of JSCE No.410/I-12)

\title{
SCALING STRONG MOTION FOURIER SPECTRA BY MODIFIED MERCALLI INTENSITY, LOCAL SOIL AND LOCAL GEOLOGIC SITE CONDITIONS
}

\author{
By M. D. TRIFUNAC*
}

\begin{abstract}
Empirical scaling of Fourier Amplitude Spectra in terms of the Modified Mercalli Intensity (M. M. I.), local soil conditions ("rock", stiff soil, and deep soil) and local geologic conditions (basement rock, intermediate sites and sites on sediments) are presented. It is suggested that both soil and geological site effects should be used together in estimation of the site specific Fourier amplitude spectra.

Keywords : strong motion earthquake spectra, site effects
\end{abstract}

\section{INTRODUCTION}

Local soil and geological site conditions influence the amplitudes of recorded seismic waves. This has been studied theoretically ${ }^{1) \sim 3)}$ and experimentally(4) ${ }^{4)}$. Through analysis of the shapes of the Fourier and response spectrum amplitudes, it was possible to describe the effects of the local soil conditions on the site response $^{9)}$ and to extend the results of Gutenberg' ${ }^{5}$ about the effects of the local geologic conditions to the high frequency spectral amplitudes ${ }^{10)}$. These studies were further refined by detailed regression analyses, which were made possible by larger numbers of well documented records of strong ground motion ${ }^{10) \sim 14)}$.

However, these studies considered either the local soil or the local geologic site conditions and never combined the simultaneous effects of both media in the development of one and more general scaling relation. Since the typical dimensions of the local soil versus the local geologic site conditions are so different one might expect that their effects would be reflected in the recorded spectral amplitudes in high and in low frequencies respectively. The purpose of this paper is to analyze this and to show how these effects should be included in the empirical scaling of Fourier amplitude spectra.

\section{SCALING OF FOURIER SPECTRA IN TERMS OF MMI, $\boldsymbol{s}, \boldsymbol{v}$ and $\boldsymbol{s}_{L}$}

\section{(1) The scaling relation}

Trifunac $^{15) .16)}$ presented empirical models for scaling of Fourier Amplitude spectra, $F S(T)$, of strong earthquake ground motion in terms of earthquake magnitude, $M$, source to station distance, $\Delta$, and characterization of local geology and soil classification at the recording site. In this paper this approach is presented for scaling of Fourier amplitude spectra in terms of Modified Mercalli Intensity (M. M. I. ) at the site, $I_{M M}$, and the local geological and soil site classifications $\left(s_{L}=0\right.$ for "rock" sites. This corresponds to

\footnotetext{
* Ph. D., Professor of Civil Eng., Univ. Southern California, Los Angeles, California, 90089-1114
} 
the soil of thickness less than $10 \mathrm{~m}$ and for materials with shear wave velocity in excess of $800 \mathrm{~m} / \mathrm{sec} . s_{L}=1$ is for stiff soil sites where the deposit thickness is between 15 and $70 \mathrm{~m} . s_{L}=2$ corresponds to deep soil sites with thickness of deposits greater than $100 \mathrm{~m}$ ). In this paper we do not consider the depth of sedimentary deposits ${ }^{16)}, h$, but replace it by the corresponding local geological site parameter ${ }^{17)} s(s=0$ for sites on sediments, $s=1$ for intermediate sites and $s=2$ for sites on geological basement rock). Treating the site parameters as indicator variables, the scaling relation takes the form

$$
\begin{aligned}
\log _{10} F S(T)= & b_{1}(T) \hat{I}_{M M}+b_{2}^{(1)}(T) S^{(1)}+b_{2}^{(2)}(T) S^{(2)}+b_{3}(T) v \\
& +b_{4}^{(1)}(T) S^{(1)} v+b_{4}^{(2)}(T) S^{(2)} v+b_{5}(T)+b_{6}^{(1)}(T) S_{L}^{(1)}+b_{6}^{(2)}(T) S_{L}^{(2)}
\end{aligned}
$$

with $v=0$ for horizontal and $v=1$ for vertical motions. $b_{1}(T)$ through $b_{6}^{(2)}(T)$ are the empirical scaling functions. $b_{2}^{(i)}(T)$ and $b_{4}^{(i)}(T)$, for $i=1$ and 2 , are associated with the site parameters $S^{(i)}$ and $S^{(i)} v$ respectively. $S^{(1)}$ and $S^{(2)}$ represent a new pair of indicator variables for local geological site conditions :

$$
S^{(1)}= \begin{cases}1 & \text { if } s=1, \text { intermediate sites } \\ 0 & \text { otherwise, }\end{cases}
$$

and

$$
S^{(2)}= \begin{cases}1 & \text { if } s=2, \text { geological basement rock } \\ 0 & \text { otherwise, }\end{cases}
$$

while $S_{L}^{(1)}$ and $S_{L}^{(2)}$ characterize the soil at the site where'

$$
\begin{aligned}
S_{L}^{(1)} & = \begin{cases}1 & \text { if } s_{L}=1, \text { stiff soil sites } \\
0 & \text { otherwise, }\end{cases} \\
S_{L}^{(2)} & = \begin{cases}1 & \text { if } s_{L}=2, \text { deep soil sites } \\
0 & \text { otherwise }\end{cases}
\end{aligned}
$$

The use of the indicator variables $S^{(1)}$ and $S^{(2)}$ here instead of $s$, is due to the fact that $s$, is a qualitative variable which takes on the discrete values of 0,1 and 2 for the three distinct types of geological site classifications ${ }^{17}$.

In our recent work ${ }^{15) .16)}$ we showed that the ratio of horizontal to vertical spectral amplitudes should also depend on the local geologic conditions. Softer geological materials near ground surface bend the incident rays closer to the vertical and therefore the terms $b_{4}^{(1)}(T) S^{(1)} v$ and $b_{4}^{(2)}(T) S^{(2)} v$ have been adopted to model frequency dependent trends associated with this effect.

As in our previous analyses ${ }^{15) .16)}$ the scaling functions $b_{1}^{(7)}$ through $b_{6}^{(2)}(T)$ are determined from the regression analysis of the new database of 1482 components of spectral amplitudes, $F S(T)$ at 91 discrete periods $T$ ranging from $0.04 \mathrm{sec}$. to $15 \mathrm{sec}$. The data are first screened and selected to reduce the possible bias in the model. All procedures in data preparation, selection and the steps of regression analysis employed here are identical to those in our previous work ${ }^{15)}{ }^{16)}$. The resulting scaling functions at each period $T$ are then $\hat{b}_{1}(T)$ through $\hat{b}_{6}^{(2)}(T)$. Substituting the fitted scaling functions into equation (1) gives $\hat{F} S(T)$, the estimated spectral amplitudes, where

$$
\begin{aligned}
\log _{10} \hat{F} S(T)= & \hat{b}_{1}(T) \hat{I}_{M M}+\hat{b}_{2}^{(1)}(T) S^{(1)}+\hat{b}_{2}^{(2)}(T) S^{(2)}+\hat{b}_{3}(T) v \\
& +\hat{b}_{4}^{(1)}(T) S^{(1)} v+\hat{b}_{4}^{(2)}(T) S^{(2)} v+\hat{b}_{5}(T)+\hat{b}_{6}^{(1)}(T) S_{L}^{(1)}+\hat{b}_{6}^{(2)}(T) S_{L}^{(2)}
\end{aligned}
$$

$\hat{I}_{M M}$ is the estimated M.M. I. level at the site, or the reported M. M. I. level, if available. The new database ${ }^{15)}$ 20) has many records from the earthquakes after 1972, which have magnitudes typically below $M$ $=6$. The M. M. I. levels for these earthquakes are not well documented or are not available for many recording sites. For these sites, the M.M.I. levels have been estimated from $^{18)}$

$$
\hat{I}_{M M}=1.5 M+1.12-0.856 \ln \Delta-1.50 \Delta / 100-0.26 s
$$

The residues $\epsilon(T)=\log _{10}(F S(T))-\log _{10}(\hat{F} S(T))$ describing the distribution of the recorded $F S$ $(T)$ about the estimated $\hat{F} S(T)$ are next calculated. We assume that $\epsilon(T)$ may be described by a normal distribution function with mean, $\mu(T)$, and standard deviation, $\sigma(T)$. The probability $p(\epsilon, T)$, at period $T$, that

$$
\epsilon(T)=\log _{10}(F S(T))-\log _{10}(\hat{F} S(T))<\epsilon(T)
$$


is then given by

$$
\begin{aligned}
p(\epsilon, T)= & \frac{1}{\sigma(T) \sqrt{2 \pi}} \int_{-\infty}^{\epsilon(T)} \\
& \cdot \exp \left[-\frac{1}{2}\left(\frac{x-\mu(T)}{\sigma(T)}\right)^{2}\right] d x .
\end{aligned}
$$

\section{( 2 ) The regression coefficients}

Fig. 1 shows the smoothed coefficients $\hat{b}_{1}(T)$ through $\hat{b}_{6}^{(2)}(T)$ (solid lines) together with the estimates of their $90 \%$ confidence intervals (dashed lines). Comparison of this figure with the corresponding figures in our previous related work $^{15) .16)}$, shows that the functions $\hat{b}_{1}(T)$, $\hat{b}_{3}(T), \hat{b}_{5}(T), \hat{b}_{6}^{(1)}(T), \hat{b}_{6}^{(2)}(T)$ are similar to our previous estimates. These functions correspond to the scaling parameters: $I_{M M}, v, 1, S_{L}^{(1)}$ and $S_{L}^{(2)}$, and their similarity demonstrates the stability and consistency of this with the previous and analogous regression models.

Fig. 2 shows the plot of the residuals corresponding to $p^{*}(\varepsilon, T)=0.1$ through 0.9 for

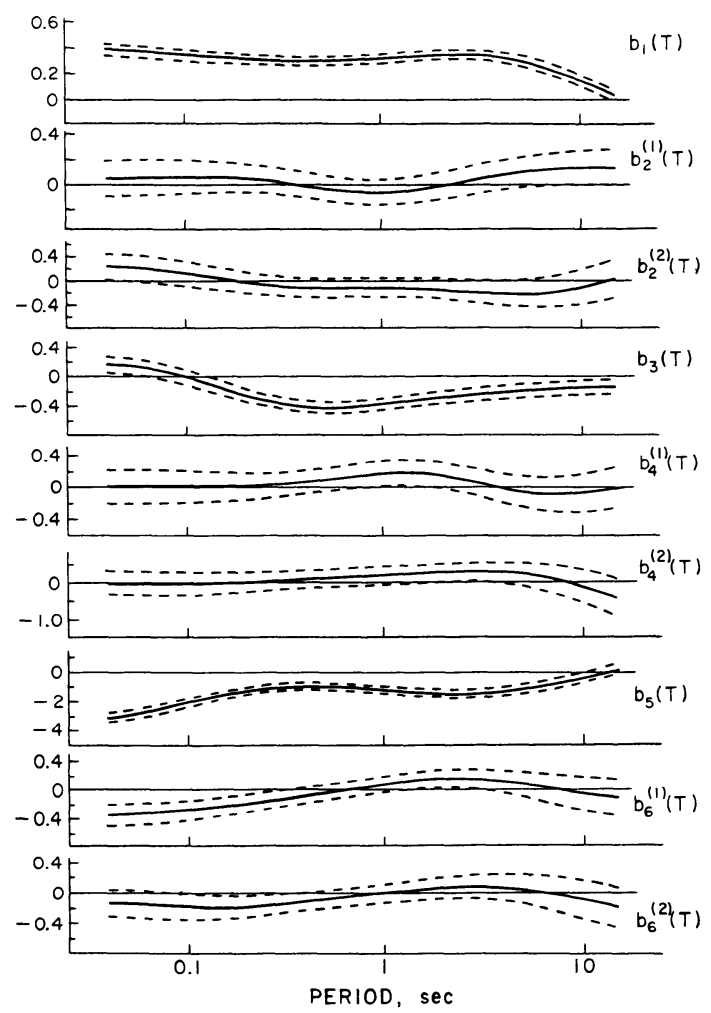

Fig. 1 Functions $\hat{b}_{1}(T)$ through $\hat{b}_{6}^{(2)}(T)$ (full lines) in equation (4) and the estimates of their 90 percent confidence intervals (dashed lines).

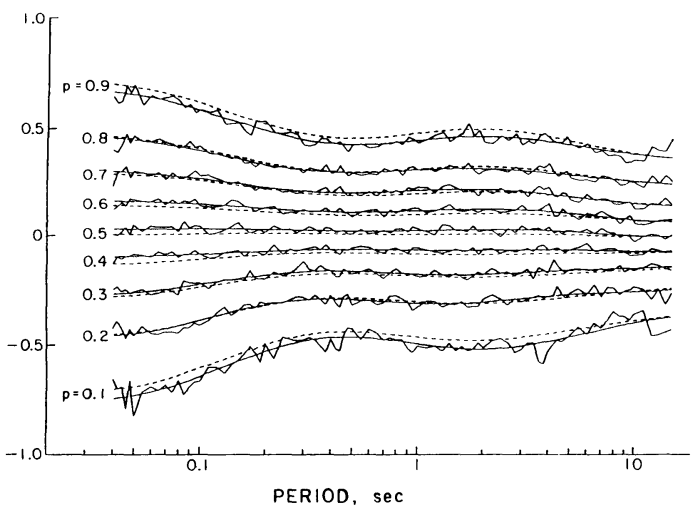

Fig. 2 Distribution of residuals (irregular full lines and smooth full lines) relative to the scaling model (4). Smooth dashed lines represent $p(\varepsilon, T)$ computed from equation (6) as an approximation to $p^{*}(\varepsilon, T)$ (full lines).

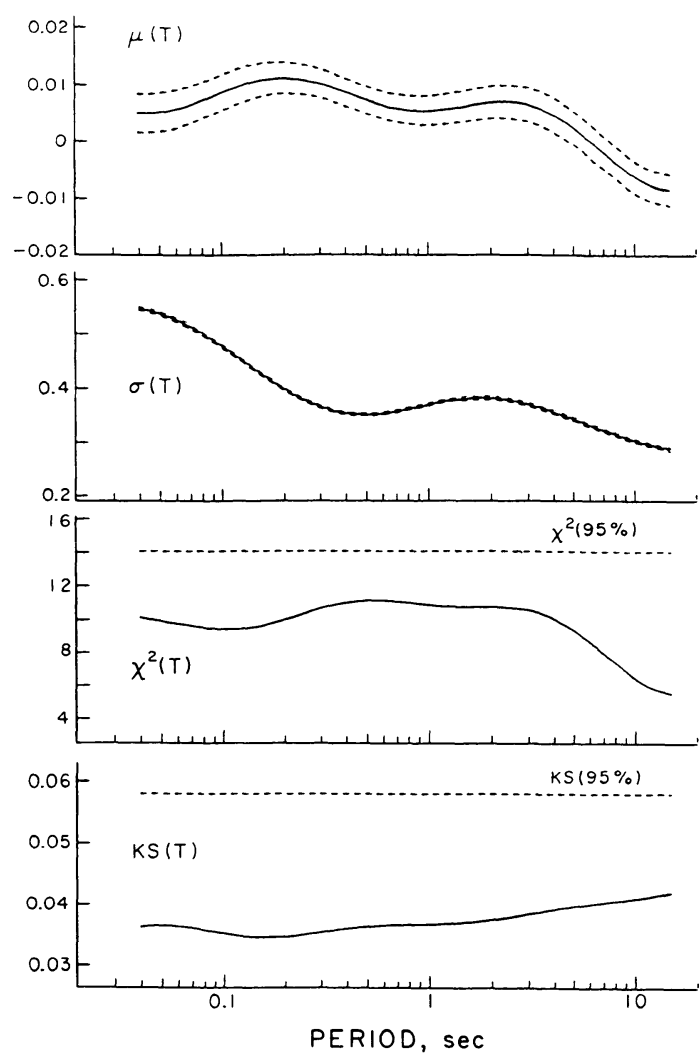

Fig. $3 \hat{\mu}(T)$ and $\hat{\sigma}(T)$ in equation (6) (full lines) and their 95 percent confidence intervals (top two diagrams). Actual (full lines) and permissible (dashed lines), with 95 percent confidence, amplitudes of the $\chi^{2}(T)$ and Kolmogorov-Smirnov, $K S(T)$, tests are shown in bottom two diagrams 
Table 1

$$
\begin{aligned}
& \log _{10} F S(T)=b_{1}(T) \hat{I}_{M M}+b_{2}^{(1)}(T) s^{(1)}+b_{2}^{(2)}(T) s^{(2)}+b_{3}(T) v+ \\
& b_{4}^{(1)} S^{(1)} v+b_{4}^{(2)}(T) S^{(2)} v+b_{5}(T)+b_{6}^{(1)}(T) s_{L}^{(1)}+b_{6}^{(2)}(T) S_{L}^{(2)}
\end{aligned}
$$

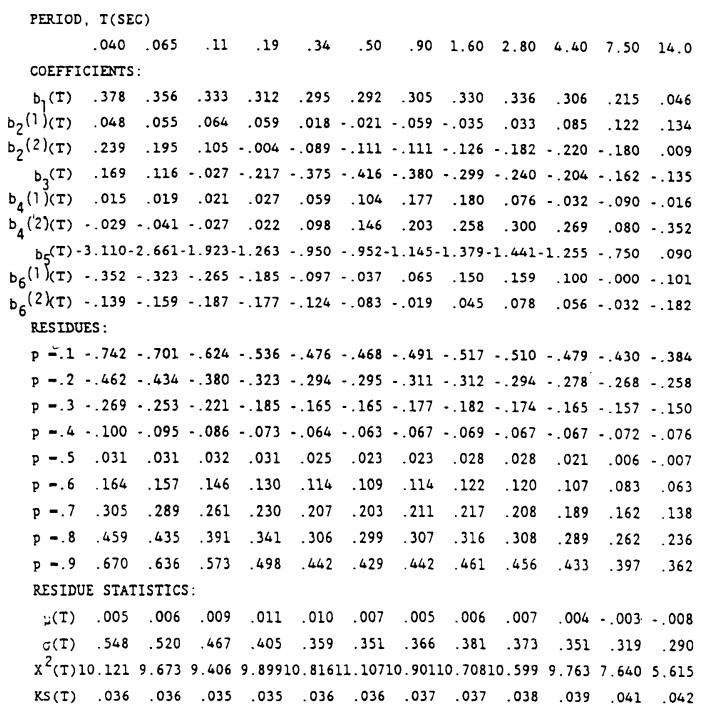

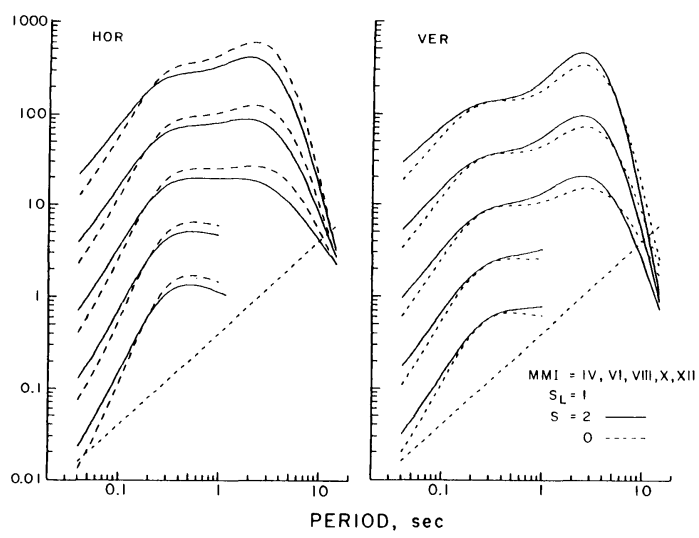

Fig. 4 Estimated Fourier Amplitude spectra (inches/sec.), $p$ $(\varepsilon, T)=0.5$, for M. M. I. $=$ IV, VI, V, X and XI , stiff soil site $\left(s_{L}=1\right)$, site on basement rock $(s=2)$ (full lines) site on sediments $(s=0)$ (dashed lines), and for horizontal (left) and vertical (right) motions.

$\log _{10} F S(T)$. Comparison with the analogous figures in our previous work ${ }^{15)}$.16) shows that the uncertainties associated with the characterization of local site geology in terms of site conditions ${ }^{17)}(s=0,1$ or 2$)$ are not much greater than those associated with characterization in terms of the depth of sediments ${ }^{16)}, h$.

Fig. 3 shows the plot of the statistical parameters employed in the description of the residues, namely, $\hat{\mu}(T), \hat{\sigma}(T), \chi^{2}(T)$ and $K S(T)$. Both the chi-squared and the Kolmogorov-Smirnov tests fail to reject the hypothesis that the distribution is normal, at the $95 \%$ level of confidence. Table 1 presents, for 12 periods, between $T=0.04 \mathrm{sec}$. and $T=14 \mathrm{sec}$, the values of the smoothed regression coefficients $\hat{b}_{1}(T), \quad \hat{b}_{2}^{(1)}(T), \quad \hat{b}_{2}^{(2)}(T), \quad \hat{b}_{3}(T), \quad \hat{b}_{4}^{(1)}(T), \quad \hat{b}_{4}^{(2)}(T), \quad \hat{b}_{5}(T), \hat{b}_{6}^{(1)}(T), \hat{b}_{6}^{(2)}(T)$, the nine smoothed calculated residue levels corresponding to the actual distribution $p^{*}(\varepsilon, T)=0.1$ through 0.9 , the smoothed coefficients $\hat{\mu}(T), \hat{\sigma}(T)$ in equation (6), the $\chi^{2}$ and the Kolmogorov-Smirnov statistics. The 12 periods presented will be sufficient for most practical computations, especially since the smoothness of the coefficients is such that any interpolation scheme will yield adequate estimates of $F S(T)$ in the entire period range from $0.04 \mathrm{sec}$. to $14 \mathrm{sec}$.

\section{(3) The estimated Fourier spectra}

Fig. 4 presents examples of Fourier amplitude spectra, $F S(T)$, computed from equation (4) for $p$ $(\varepsilon, T)=0.5$, for M. M. I. levels IV, V, VI, X and XII and for soil classification $s_{L}=1$ (stiff soil). The left figure is for horizontal $(v=0)$ and the right figure for vertical $(v=1)$ motion. The solid lines in both graphs correspond to the local geological site condition of $s=2$ (basement rock) while the dashed lines correspond to $s=0$ (sediments). The diagonal dashed lines represent the empirical average Fourier amplitudes of digitization noise. Comparison of this figure with the corresponding figures of Trifunac ${ }^{15)}$. 16), for scaling which uses the depth of sediments ${ }^{16)}, h$, shows detailed resemblance of the two scaling models. At low periods, up to $0.1 \mathrm{sec}$, the $F S(T)$ amplitudes at rock site are slightly higher than those on alluvium. This is due to the fact that at low periods $(<0.1 \mathrm{sec}$. $), S_{L}^{(2)}\left(s_{L}=2\right)$ is slightly positive, though close to zero. Since on the linear amplitude scale $S_{L}^{(2)}$ represents a factor modifying spectral amplitudes for $s_{L}=2$ (deep soil sites) relative to $s_{L}=0$ ("rock" soil sites), positive values of $s_{L}^{(2)}$ indicate relative amplifications. 


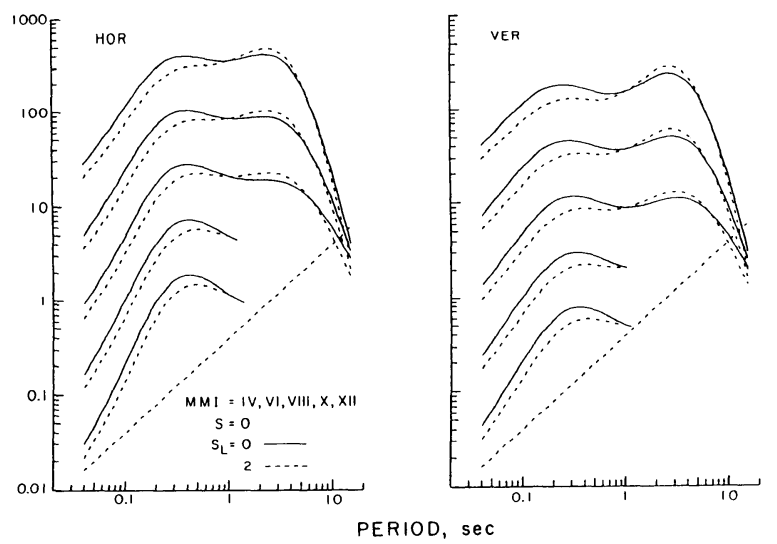

Fig. 5 Estimated Fourier Amplitude spectra (inches/sec.), $p(\varepsilon, T)=0.5$, for M. M. I. $=$ IV, VI, W. X and XII, site on sediments ( $s$ $=0)$ for "rock" site $\left(s_{L}=0\right)$ (full lines) and for site on deep soil $\left(s_{L}=2\right)$ (dashed lines) and for horizontal (left) and vertical (right) motions.

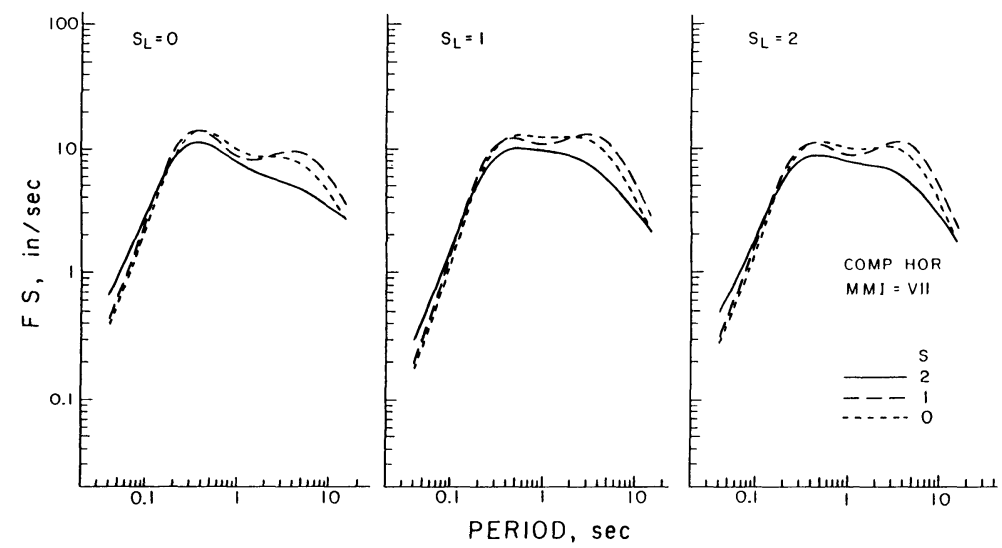

Fig. 6 Estimated Fourier Amplitude spectra (inches/sec.), $p(\varepsilon, T)=0.5$, for M. M. I. $=$ U, horizontal motions, basement rock sites $(s=2)$ (full lines), intermediate sites $(s=1)$ (long dashed lines), and on sediments $(s=0)$ (short dashed lines), and for "rock" sites $\left(s_{L}=0\right)$ (left), stiff soil $\left(s_{L}=1\right)$ (center) and deep soil $\left(s_{L}=2\right)$ (right).
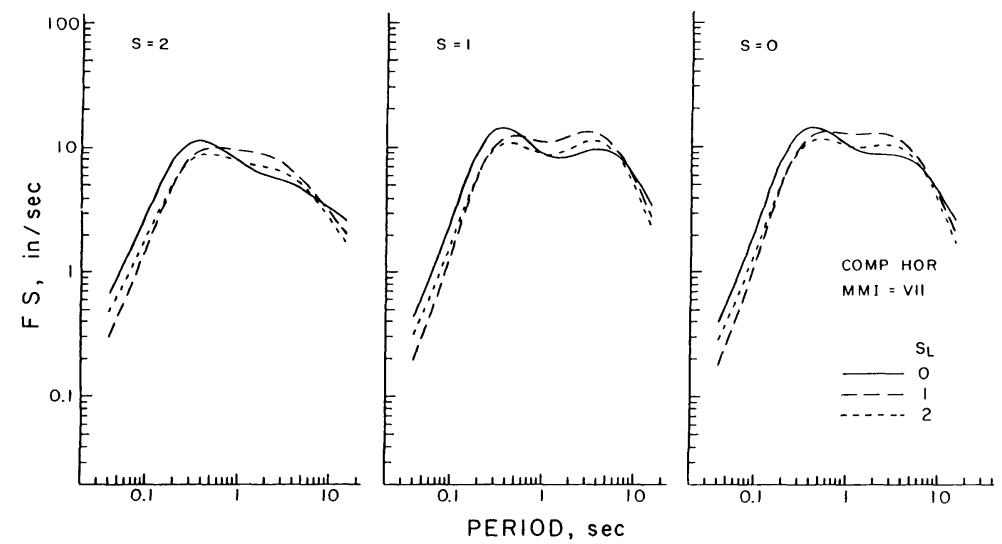

Fig. 7 Estimated Fourier Amplitude spectra (inches/sec.), $p(\varepsilon, T)=0.5$, for M. M. I. $=$ UI, horizontal motions, "rock" sites ( $\left.s_{L}=2\right)$ (short dashed lines) and for basement rock site $(s=2)$ (left), intermediate sites $(s=1)$ (center) and site on sediments $(s=0)$ (right) 
Fig. 5 presents another set of estimated spectra to illustrate the effect of local soil conditions on the $F S$ (T) amplitudes. The $F S(T)$ have been computed for various M. M. I. levels (IV, VI, VI, X and XII) and for the local geological site condition $s=0$ (sediments). The left part of this figure is for horizontal $(v=0)$ and the right one for vertical $(v=1)$ motions. The solid lines in both figures correspond to the local soil classification $s_{L}=0$ ("rock") and the dashed lines to $s_{L}=2$ (deep soil). As in the work for the model which employs the depth of sediments ${ }^{16)}, h$, the $F S(T)$ amplitudes at "rock" sites $\left(s_{L}=0\right)$ are higher than those at deep soil sites $\left(s_{L}=2\right)$. This trend is observed here up to about $1 \mathrm{sec}$. period, beyond which the trend is reversed.

Fig. 6 and 7 compare the effects of local geologic site conditions $(s)$ and of local soil classifications $\left(s_{L}\right)$ on $F S(T)$. Fig. 6 shows that for all soil site classifications $\left(s_{L}=0,1\right.$ or 2$)$, the Fourier amplitudes, FS $(T)$ are higher at alluvium sites $(s=0)$ than at rock sites $(s=2)$ for periods longer than about $0.1 \mathrm{sec}$. Fig.7 shows that the $F S(T)$ amplitudes for local soil classification $s_{L}=0$ are higher than those for stiff soil $\left(s_{L}=1\right)$, or deep soil $\left(s_{L}=2\right)$, for periods up to about $0.5 \mathrm{sec}$. Between about $0.5 \mathrm{sec}$. to approximately $8 \mathrm{sec}$, this trend is reversed.

Fig. 8 and 9 present examples of how the horizontal and vertical Fourier spectrum amplitudes computed from equation (4) compare with the actural Fourier spectra for the corresponding components of recorded

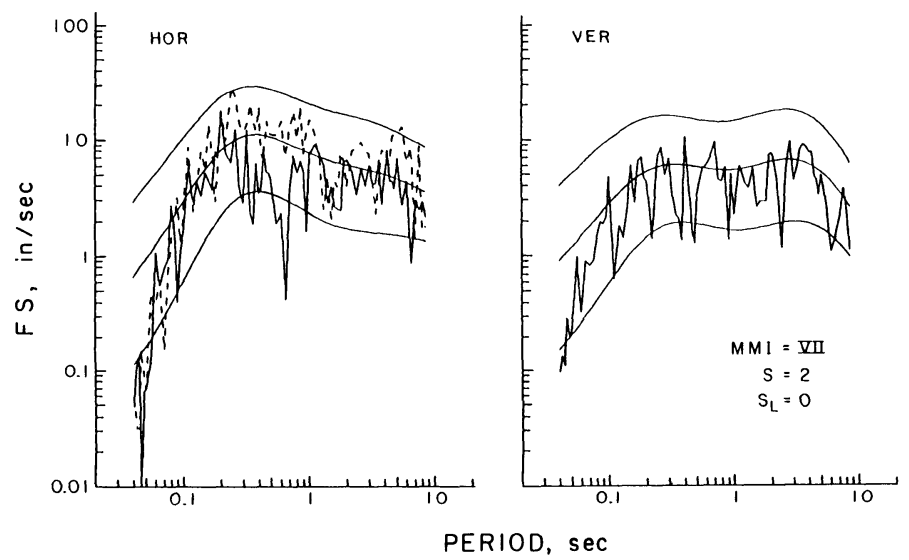

Fig. 8 Comparison of actual (AG 106 CALTECH SEISMOLOGICAL LAB 1971, M. M. I. = I, $s=2, s_{L}=0$ ) and estimated Fourier spectrum amplitudes for $p(\varepsilon, T)=0.1,0.5$ and 0.9 and for horizontal (left) and vertical (right) motion.

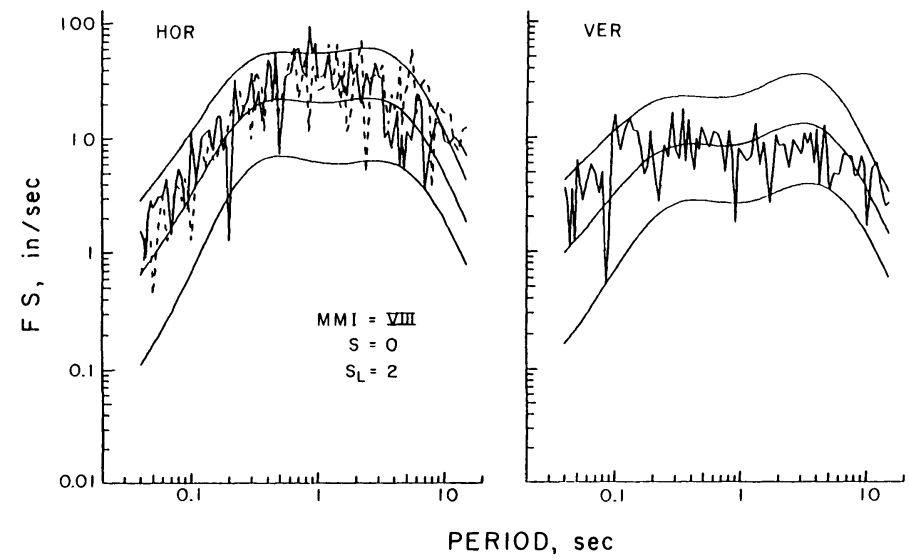

Fig. 9 Comparison of actual (AA 001 El CENTRO, 1940, M. M. I. $=$ VI, $s=0, s_{L}=2$ ) and estimated Fourier spectrum amplitudes for $p(\varepsilon, T)=0.1,0.5$ and 0.9 and for horizontal (left) and vertical (right) motion. 
strong motion data at typical sites.

\section{DISCUSSION AND CONCLUSIONS}

The aim of this paper has been to present the empirical scaling equations for representation of the Fourier spectrum amplitudes of the observed strong earthquake ground motions. The functional form of the empirical equations used is not new, but has evolved, with minor refinements, from our previous work $^{10)}$.12) 14). 19). The idea, which has been introduced here for the first time, is to use the local soil and the local geologic characteristics of the site simultaneously in the development of the regression models. Also, the term, $S^{(i)} v$, reflecting the directional dependence of the amplification has not been employed in our analyses prior to 1987 .

We found that the model fits the data ${ }^{20)}$ quite well and that there is much consistency of this and other regression models which deal with similar scaling ${ }^{15)}{ }_{16}$. In terms of the observed amplitudes of the residuals, the spectral amplitudes scaled ${ }^{16)}$ by the magnitude parameter, $M$, fit the data better than the spectra scaled in terms of the MMI at the site. However, relative to our previous studies ${ }^{13) .19)}$, the amplitudes of the residuals we found in this investigation are smaller.

To enable qualitative comparison of our results, summarized in this paper, with some earlier investigations ${ }^{9}$, which employed the local site characterization in terms of the local soil classification only, we carried out such analyses as well, by ignoring the local geologic features of the sites ${ }^{15}$. Since the functional form of the dependence of the spectral amplitudes on the depth of sediments is simmilar to its dependence on the local soil conditions, we found that ignoring the local geologic conditions may lead to exaggerated amplitude factors "representing" the local soil conditions. Thus, we conclude that both the local soil and the local geologic site conditions must be used together in the selection of the site specific Fourier amplitude spectra.

\section{ACKNOWLEDGEMENTS}

This work was initiated at Department of Civil Engineering, University of Southern California in Los Angeles, California. It was completed at the School of Civil Engineering, Kyoto University, with generous support trom the Japan Society for Promotion of Science.

\section{REFERENCES}

1) Haskell, N. : Crustal Reflection of Plane SH Waves, J. Geoph. Res., Vol.65, pp. 4147-4150, 1960.

2) Tsai, N. C. : Influence of Local Geology on Earthquake Ground Motion, EERL, Calif. Inst. of Tech., Pasadena, 1969.

3) Trifunac, M. D. : Surface Motion of Semi-Cylindrical Alluvial Valley for Incident Plane SH Waves, Bull. Seism. Soc. Amer., Vol. 61, pp. 1755-1770, 1971.

4) Kanai, K. : Relation Between the Earthquake Damage of Non-Wooden Buildings and the Nature of the Ground, Bull. Earthquake Res. Inst., Vol.27, p. 97, 1949; Vol.29, p. 209, 1951.

5) Gutenberg, B. : Effects of Ground on Earthquake Motion, Bull. Seism. Soc. Amer., Vol. 47, pp. 221-520, 1957.

6) Duke, M. : Effects of Ground on Destructiveness of Large Earthquakes, Proc. ASCE, Vol. 84, No. SM 3, 1958.

7) Medvedev, S. V. : Ocenka Seizmicheskoi balnosti u zavisimosti ot gruntovih uslovi, Tr. Geofiz. Inst. AN SSSR No. 4 (141), 1955.

8) Zhou, Xi-Yuan : Effect of Soil Conditions on Structural Damage During Strong-Motion Earthquakes, Earthquake Eng. Research Report Vol. II, pp. 27-43, Institute of Engineering Mechanics, Academia Sinica, Harbin, China, 1965.

9) Seed, H. B., Ugas, C. and Lysmer, J. : Site Dependent Spectra for Earthquake Resistant Design, Bull. Seism. Soc. Amer., Vol.66, pp. 221-243, 1976.

10) Trifunac, M. D. : Preliminary Empirical Model for Scaling Fourier Amplitude Spectra of Strong Ground Acceleration in Terms of Earthquake Magnitude, Source to Station Distance and Recording Site Conditions, Bull. Seism. Soc. Amer., Vol.66, pp. 1343-1373, 1976.

11) Trifunac, M. D. : Preliminary Empirical Model for Scaling Fourier Amplitude Spectra of Strong Motion Acceleration in Terms of Modified Mercalli Intensity and Geologic Site Conditions, Int. J. Earthquake Eng. and Structural Dynamics, Vol.7, pp. 63-74, 1979. 
12) Trifunac, M. D. and Lee, V. W. : Frequency Dependent Attenuation of Strong Earthquake Ground Motion, Int. J. Soil Dynamic and Earthquake Eng., 1989 (in press).

13) Trifunac, M. D. and Lee, V. W. : Empirical Models for Scaling Fourier Amplitude Spectra of Strong Ground Acceleration in Terms of Earthquake Magnitude, Source to Station Distance, Site Intensity and Recording Site Conditions, Int. J. Soil Dynamics and Earthquake Eng., Vol. 8, No. 3, pp. 110-125, 1989.

14) Trifunac, M. D. and Lee, V. W. : Empirical Models for Scaling Pseudo Relative Velocity Spectra of Strong Earthquake Accelerations in Terms of Magnitude, Distance, Site Intensity and Recording Site Conditions, Int. J. of Soil Dynamics and Earthquake Eng., Vol. 8, No. 3, pp. 126-144, 1989.

15) Tifunac, M. D. : Influence of Local Soil and Geologic Site Conditions on Fourier Spectrum Amplitudes of Recorded Strong Motion Accelerations, Dept. of Civil Eng. Report No. CE 87-04, Univ. Southern California, Los Angeles, California, 1987.

16) Tifunac, M. D. : Dependence of Fourier Spectrum Amplitudes of Recorded Strong Earthquake Accelerations on Magnitude, Local Soil Conditions and on Depth of Sediments, Int. J. Earthquake Eng. and Structural Dyn. 1989 (in press).

17) Trifunac, M. D. and Brady, A. G. : On the Correlation of Seismic Intensity Scales with the Peaks of Recorded Strong Ground Motion, Bull. Seism. Soc. Amer., Vol.65, pp. 139-162, 1975.

18) Lee, V. W. and Trifunac, M. D. : Attenuation of Modified Mercalli Intensity for Small Epicentral Distance in California, Dept. of Civil Eng. Report No. CE 85-01 Univ. Southern Calif., Los Angeles, California, 1985.

19) Trifunac, M. D. and Lee. V.W. : Preliminary Empirical Model for Scaling Pseudo Relative Velocity Spectra of Strong Earthquake Accelerations in Terms of Magnitude, Distance, Site Intensity and Recording Site Conditions, Dept. of Civil Eng. Report No. CE 85-04, Univ. Southern Calif., Los Angeles, California, 1985.

20) Lee, V. W. and Trifunac, M. D. : Strong Earthquake Ground Motion'Data in EQINFOS : Part 1, Dept. of Civil Eng. Report No. CE 87-01, Univ. of Southern Calif., Los Angeles, California, 1987.

(Received October 5 1988) 